\section{Europäische Dividende}

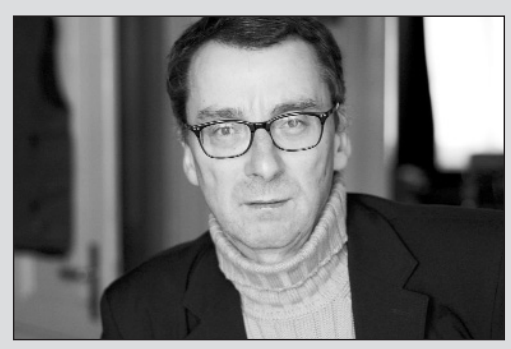

Nun schon wieder Europa, mag manche geplagte Führungskraft denken oder auch sagen. Als hätte man nicht schon Baustellen genug, von Basel II bis zum Persönlichen Budget. Von dem österreichischen Philosophen und Ökonomen Otto Neurath stammt das schöne Bild, wir seien wie Schiffer, die ihr Schiff auf offener See umbauen müssten, ohne es jemals in einem Dock zerlegen und aus besten Bestandteilen neu errichten zu können.

Eine gewisse Rat- und Mutlosigkeit sei in der Debatte um die künftige Gestaltung des Sozialen festzustellen, konstatiert in diesem Heft Prof. Dr. Johannes Degen, bis zu seiner Pensionierung Ende letzten Jahres Direktor der Evangelischen Stiftung Hephata in Mönchengladbach. Angst vor einer mutigen Zeitansage sei überall zu spüren. Eine kurzatmige Spar- und Reformhektik überdeckt diese Befindlichkeitslagen. Dabei wird den Bürgern eine öffentliche Diskussion darüber erspart, was kollektiv leistbar ist und wie wir künftig leben wollen (Seite 11).

Aber vielleicht kann »Europa « gerade beim Aufbrechen dieser Situation helfen. Dann nämlich, wenn man bei diesem Schlagwort nicht zuerst an Brüssel oder Vergaberecht denkt, sondern neugierig darauf ist, wie Menschen in anderen Ländern die oft gleichen Probleme wie die unsrigen lösen.

Der Blick über den Zaun verspricht reiche Ernte, so Peter Erath in seinem Beitrag in diesem Heft: Mit europäischen Partnern kann Wissen kostengünstig generiert, transferiert und implementiert werden. Die deutsche Sozialwirtschaft kann, wenn sie das Thema ernst nimmt, mit einer europäischen Dividende rechnen, vom Risiko-Management über ethische Codes bis zur Nutzerbeteiligung (Seite 19).

Was das praktisch im Unternehmensalltag heißen kann, ist ein Thema des nächsten Kongresses der Sozialwirtschaft, der sich am 26. und 27. April 2007 in Magdeburg mit dem Thema »Europa sozial managen. Werte, Wettbewerb, Finanzen « befassen wird ( $\mathrm{vgl}$. Seite 14 und 15).
Universitatsabschluss

Sortalmanagement

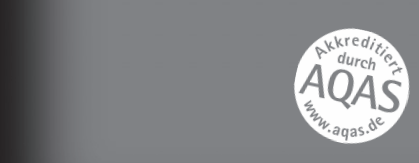

Masterstudiengang

Berufsbegleitend für Führungskräfte im Sozialund Gesundheitswesen

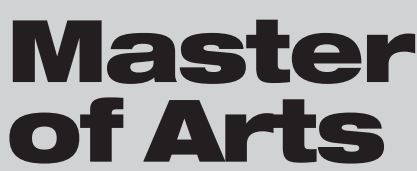

in Social Services Administration

Praxisorientiert

Interdisziplinär

Bewerbungen bis:

31.01.2007 für das SS 2007

Unterlagen anfordern beim: Institut für

Diakoniewissenschaft

Fliednerstraße 2

45481 Mülheim an der Ruhr

Tel.: (02 08) 48 43-151

info@ifd.fliedner.de

www.ifd.fliedner.de

Veranstaltungsort:

Fliedner Akademie

in Duisburg

\section{universitätbonn}

Institut für interdisziplinäre und angewandte Diakoniewissenschaft an der Universität Bonn 